\section{P298 THYROID CANCER PATIENT'S FERTILITY AFTER RADIOACTIVE IODINE THERAPY}

Kristina Vabalayte*, Anatoly Romanchishen. St. Petersburg State Pediatric Medical University, St. Petersburg, Russian Federation

10.1136/archdischild-2019-epa.648

Background For patients with differentiated thyroid carcinoma (DTC), the effect of radioactive iodine (RAI) therapy on gonadal and reproductive function is an important consideration.

Objective and methods 127 children were operated on thyroid in case of DTC during 1975-2015. 87 pts were treated by RAI (1-13 times). Average age is 15 years (4-18). Histological types of DTC were papillary (69\%), follicular (27\%), other $(4 \%)$. Average follow up period is 3 year $(2-40)$. We analyzed effect of therapeutic RAI on sex steroid level; on ovarian function, menses, ovulation in women; sperm in men; future fertility; pregnancy outcomes.

Results Early side effects (during $1^{\text {st }}$ week after RAI) includednausea and vomiting(29\%), sialoadenitis (22\%), temporal bone marrow dysfunction (6\%). Late side effects included permanent salivary glands' dysfunction (2\%), permanent bone marrow dysfunction (4\%), lung fibrosis (5\%), second tumors leucosis, breast cancer (4\%), fertility disorder (7\%). Fertility was analyzed in 78 pts. Sterility (2\%), amenorrhea (4\%), changes in menstrual period (5\%), miscarriage (4\%).

Conclusion RAI should be prescribed only for indications. Sexual cell should be cryopreserve before RAI.

\section{P299 REVIVAL OF A NEWBORN SCREENING PROGRAM IN THE PEOPLE'S DEMOCRATIC REPUBLIC OF LAOS}

${ }^{1}$ Thomas Hoehn*, ${ }^{2}$ Bounnack Saysanasongkham. ' University Hospital Duesseldorf, Duesseldorf, Germany; ${ }^{2}$ Ministry of Health, Vientiane, Lao, People's Democratic Republic

10.1136/archdischild-2019-epa.649

Background Neonatal screening programs have been established and are in use in most countries worldwide. Laos belongs to the few countries which still have not established any kind of newborn screening.

Description Participants of an initial pilot project between 2008 and 2010 were the large maternity hospitals within the city of Vientiane (Mahosot Hospital [2.500 deliveries], Sethathirath Hospital [2.000 deliveries], Friendship Hospital [700 deliveries], and Mother \& Child Health Hospital [3.500 deliveries]). Samples were taken immediately prior to hospital discharge and once weekly air-shipped to a German screening laboratory.

Lession learned Altogether 11.362 samples of newborn infants have been examined. The rate of retests was above European average due to very early discharge policies in Laotian maternity hospitals. Confirmed cases of neonatal congenital diseases included two infants with hypothyroidism and one infant with congenital adrenal hyperplasia without salt-loss. All three infant received early therapy and are currently doing well.

Next steps To re-establish newborn screening in a sustained manner following the demonstration of feasibility during the pilot project. Newborn screening for TSH will be initiated in early 2019 in all delivery hospitals in the urban area of Vientiane, capital of Laos. As opposed to the pilot project, measurements in the lab will take place within the country at the laboratory of the largest delivery hospital in Vientiane, the Mother \& Newborn Hospital.

\section{P300 INVESTIGATION OF THE ASSOCIATION BETWEEN INFANTILE SKIN CONDITIONS AND THE MAIN DIETARY FACTORS: A NATIONAL COHORT STUDY}

${ }^{1}$ Shauna Quinn*, ${ }^{2}$ Lina Zgaga, ${ }^{2}$ Cristina Taut. 'Paediatrics, Trinity College Dublin, Dublin, Ireland; ${ }^{2}$ Public Health and Primary Care, Trinity College Dublin, Dublin, Ireland

\subsection{6/archdischild-2019-epa.650}

Aims Skin conditions are common amongst infants. A topic of particular interest is whether or not eczema is associated with the main dietary factors of the infant within the first nine months. The dietary factors investigated are breastfeeding duration, artificial formula feeding, timing of introduction of formula and solids. Data was acquired from the Growing Up in Ireland: National Longitudinal Study, following the progression of two cohorts of children aged 9 years and 9 months. The aim of this study is to investigate the association between skin conditions and the main dietary factors in a sample of 9 . month old infants.

Methods The study population (9,326 infants) examined was Wave 1 of the infant cohort of Growing Up in Ireland. Large numbers of covariates were investigated, as a result of existing literature. Chi-square tests were performed for analyses of the association between diagnosed skin conditions and the categorical variables chosen. T-tests of differences in the mean and 95\% CI's estimation were employed for all continuous variables. During the analysis, skin conditions were characterised as a binary variable. All variables were considered in the multivariable logistic regression model, excluding insignificant variables from the final model.

Results Introduction of artificial formula was found to have a positive association with diagnosed skin conditions in the infant $(\mathrm{OR}=0.999,95 \% \mathrm{CI}: 0.997-1$, p-value $=0.02226)$. Earlier introduction led to a higher risk of skin conditions. Breastfeeding duration and introduction of solids were not associated with neonatal skin conditions. Maternal stress $(\mathrm{OR}=1.01,95 \% \mathrm{CI}: 1.00-1.02, \mathrm{P}$-values $=0.05)$ and smoking in the household during pregnancy $(\mathrm{OR}=0.90,95 \% \mathrm{CI}$ : $0.82-$ 0.98, P-value $=.02$ ) have suggestive associations with skin conditions.

Conclusion Early introduction of artificial formula has a positive association with skin conditions in infants, while breastfeeding duration and introduction of solids may have no correlation. This study highlights the importance of the WHO recommendation of exclusive breastfeeding for 6 months.

\section{P302 ALCOHOL CONSUMPTION \& BREASTFEEDING: A REVIEW OF THE EVIDENCE}

Paul Mullane*, Mary T O'Mahony. Department of Public Health HSE South, Cork, Ireland

\subsection{6/archdischild-2019-epa.651}

Background/Aims The benefits of breastfeeding for the mother-infant dyad are recognised. Every effort should be made to encourage and facilitate women to breastfeed successfully. The use of alcohol in the context of breastfeeding is the subject of debate. Guidance can be conflicting and a potential source of confusion. The HSE Alcohol Programme requested public health expertise to undertake a review of the evidence to provide clarity for women. Low-risk alcohol consumption was the context ( $<11$ standard drinks per week; standard

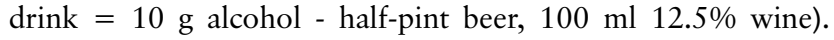

